\title{
Somatostatin analogue inhibits the mobility of prostate carcinoma cells: A new therapeutic method for advanced prostate carcinoma
}

\author{
XIAOYAN TANG ${ }^{1}$, SUSUMU TAKEKOSHI ${ }^{1}$, JOHBU ITOH $^{3}$, SHINOBU UMEMURA ${ }^{1}$, \\ SUNAO SHOJI $^{2}$, TOSHIRO TERACHI ${ }^{2}$ and ROBERT YOSHIYUKI OSAMURA ${ }^{1}$ \\ Departments of ${ }^{1}$ Pathology, and ${ }^{2}$ Urology, ${ }^{3}$ Teaching and Research Support Center, \\ Tokai University School of Medicine, Isehara, Kanagawa 259-1193, Japan
}

Received June 4, 2010; Accepted July 23, 2010

DOI: 10.3892/ijo_00000759

\begin{abstract}
The somatostatin analogue (SA) Octreotide has been used as a therapeutic reagent for somatostatin receptor type 2a (SSTR2a)-positive cancers. The purpose of this study is to detect SSTR2a in human prostate carcinomas and to elucidate the effects of SA on SSTR2a-positive prostate carcinoma cells to determine the potential of this drug as a new therapeutic method for advanced prostate carcinoma. Immunohistochemical study of SSTR2a was performed on 95 prostate carcinoma cases, and the results showed expression of SSTR2a in 14 of the 95 cases (14.74\%); the histological grade (Gleason) and capsular invasion of the prostate carcinoma were directly related to SSTR2a expression. Among the ten cases of lymph node metastasis, SSTR2a expression was markedly higher. In vitro studies were performed using SSTR2a-positive prostate cancer cells, DU145 and PC3. Migration and invasion abilities of DU145 and PC3 cells were inhibited by $\mathrm{SA}$ in a dose-dependent manner. This inhibition was reversed by Rho-kinase inhibitor Y-27632. Morphological changes of the prostate cancer cells treated with SA and Y27632 corroborate the migration and invasion assays, although SA had no effect on proliferation of DU145 and PC3 cells. In conclusion, the somatostatin analogue may be beneficial for patients with advanced prostate carcinoma or to protect from distal metastasis if they are positive for SSTR2a.
\end{abstract}

\section{Introduction}

Somatostatin was discovered as an inhibitor of growth hormone secreted by the pituitary gland, and it is distributed in many human organs and tumors (1). Somatostatin attracted our attention because of its (a) antiproliferative effects by regulating phosphotyrosine phosphatase activities to inhibit the PI3 kinase and MAP kinase activities through its G

Correspondence to: Dr XiaoYan Tang, Department of Pathology, Tokai University School of Medicine, Shimokasuya 143, Isehara, Kanagawa 259-1193, Japan

E-mail: t-xiaoya@is.icc.u-tokai.ac.jp

Key words: prostate carcinoma, somatostatin, somatostatin receptor 2a, somatostatin analogue protein-coupled receptor (SSTR1-5), (b) ability to induce apoptosis $(1,2)$, and (c) ability to indirectly inhibit tumor growth by down-regulating the secretion of growth-promoting hormones and growth factors via inhibition of calcium channels (1). Somatostatin analogue (SA) has been used as a therapeutic reagent for somatostatin receptor type 2a (SSTR2a)positive cancers owing to its inhibitory action against cell proliferation through perturbation of the PI3 kinase and RAS pathways (3).

The GTP-binding protein, Rho, is considered an essential component of the signal transduction pathway regulating focal adhesion and actin stress fiber formations (4), and is known to have various cellular functions (5). The Rho GTPase family, including RhoA, Cdc42, and Rac1, has been implicated in the regulation of integrin-mediated cell substratum adhesion (6). It is also known that microtubules contain signal molecules, which regulate the formation of actin stress fiber and focal adhesion in cultured cells by activating the Rho signal cascade (7), and Y-27632 is a specific inhibitor of Rhoassociated kinases (8). Somatostatin can inhibit the activation of Rho and cell migration in CCL39 fibroblasts (9), and its analogue induces rapid morphological changes in neuroendocrine cells (10).

In human prostate cancers, although hormonal therapy is useful and sensitive for androgen receptor (AR)-positive cases, therapy is very limited for androgen-independent, advanced or recurrent cases (11). SSTR1 $(12,13)$ and SSTR1, 2, 5 (14) are expressed in prostate carcinomas, and SSTR1 is a prognostic biomarker for prostate cancer (13). Prostate carcinoma cell lines, LNCap (androgen-dependent), PC3, and DU145 (both androgen-independent) also express SSTR1-5 $(15,16)$. It has been confirmed that SA can inhibit the growth and metastasis of PC3 cells injected into nude mice (17). The purpose of this study is to determine whether SSTR2a is expressed in human prostate carcinomas, and to elucidate the effects of SA on SSTR2a-positive prostate carcinoma cells to determine the potential of this drug as a new therapeutic reagent for advanced prostate carcinoma.

\section{Materials and methods}

Prostate carcinoma tissues. Formalin-fixed and paraffinembedded sections from 95 prostate carcinoma cases were 

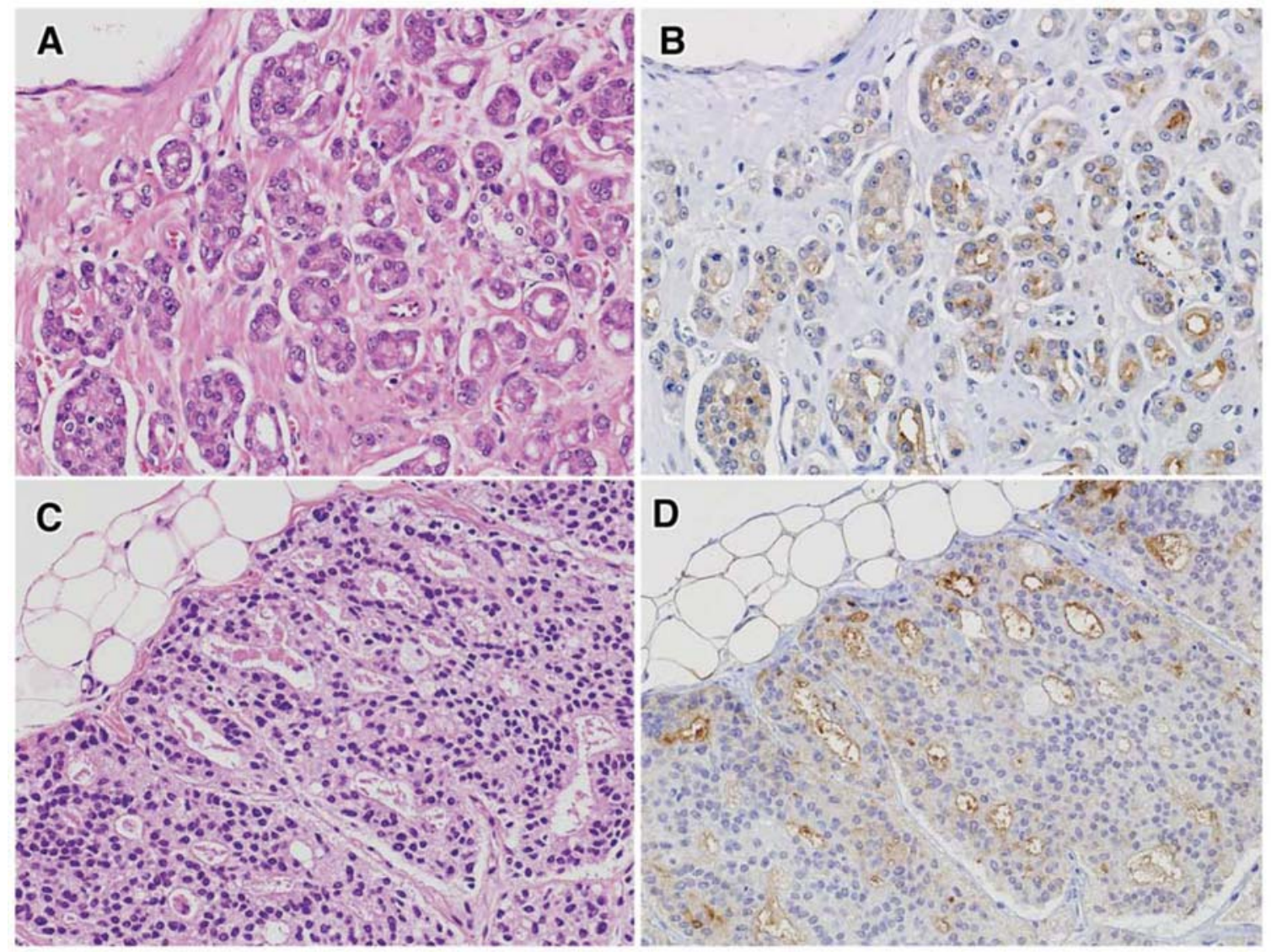

Figure 1. SSTR2a was expressed in prostate adenocarcinoma cells and associated metastatic carcinoma cells of the lymph nodes. (A) Prostate adenocarcinoma, H\&E stain. (B) Prostate adenocarcinoma, SSTR2a immunohistochemical study. (C) Metastatic prostate adenocarcinoma cells in lymph node, H\&E stain. (D) Metastatic prostate adenocarcinoma cells in lymph node, SSTR2a immunohistochemical study.

analyzed. They included 94 radical prostatectomy cases and 1 TUR-P case, 10 associated with metastatic lymph nodes.

Immunohistochemistry. The immunohistochemical study was performed by the Envision method using SSTR2a antibody (Gramsch Laboratories, 1:500 dilution). Cases were considered 'positive' if immunostaining was detected on the cell membrane or luminal surface, and if any SSRT2a-stained cells were identified. Percentage or intensity scoring was not performed. The judgment was made by two pathologists, and they were blinded to the outcome/clinical information.

Cell culture. The prostate carcinoma cell line DU145 (TKG 0604, androgen-independent), produced from metastatic organs, and the prostate cancer cell line LNCap (TKG 0603, androgen-dependent), used as a control, were provided by the Cell Resource Center for Biomedical Research, Institute of Development, Aging, and Cancer at Tohoko University. PC3 cells (ATCC no. CRL-1435, androgen-independent) were purchased from American Type Culture Collection. Cells were cultured as a monolayer in DMEM medium (Invitrogen, Carlsbad, CA) supplemented with $10 \%$ fetal bovine serum, $100 \mathrm{U} / \mathrm{ml}$ penicillin, and $100 \mu \mathrm{g} / \mathrm{ml}$ streptomycin at $37^{\circ} \mathrm{C}$ in a humid atmosphere of $5 \% \mathrm{CO}_{2} / 95 \%$ air.

Quantitative real-time PCR (RT-PCR). The RNeasy Mini $\mathrm{kit}^{\circledR}$ (Qiagen, Valencia, USA) was used to extract total RNA from fresh samples of the prostate carcinoma cell lines
DU145, PC3, and LNCap. Following digestion of DNA with RNase-free DNase I, first strand cDNA was synthesized from total RNA by reverse transcription using Super Script III (Invitrogen, California, USA). A quantitative analysis of SSTR2a (Hs00265624_s1) and RhoA (Hs00357608_ml) expression was performed using the TaqMan Gene Expression System (Applied Biosystems, Foster City, CA). Total amounts of RNA in samples were estimated by comparing with control GAPDH mRNA levels.

\section{Cell migration and invasion assays}

Cell migration assay (wound-healing assay). DU145 and PC3 cells were first seeded in 24-well plates and incubated for $24 \mathrm{~h}$ at $37^{\circ} \mathrm{C}\left(3 \times 10^{4}\right.$ cells/well $)$. After rinsing with $10 \mathrm{nM}$ phosphate-buffered saline (PBS), medium with or without Octreotide (Novartis Pharma, Sweden) was replaced. Experimental wounds were made by dragging a plastic pipette tip across the centre of the culture plate. Incubation was continued under the same conditions as before. Fixation and staining with Diff-Quik (International Reagent, Kobe, Japan) were performed at $24 \mathrm{~h}$ after incubation. Migration was evaluated by the average distances between the furthest migrated cells to the scraped edge on both sides. Rho kinase-inhibitor Y$27632\left(10^{-4} \mathrm{M}\right)$ was also used alone or in combination with Octreotide in the wound-healing assay.

Invasion assay (Matrigel assay). DU145 and PC3 cells $\left(2 \times 10^{4}\right.$ cells per $\left.500 \mu \mathrm{l}\right)$ with or without $10^{-4} \mathrm{M}$ Octreotide in 
Table I. Clinical and pathological features of SSTR2a-positive prostate carcinoma.

\begin{tabular}{|c|c|c|c|}
\hline & Positive & $\begin{array}{c}\text { SSTR2a } \\
\text { Negative }\end{array}$ & P-value \\
\hline Histologic grade & & & 0.0026 \\
\hline High & $10(10.53 \%)$ & $24(25.26 \%)$ & \\
\hline Low & $4 \quad(4.21 \%)$ & $57(60.00 \%)$ & \\
\hline Capsule invasion & & & 0.0041 \\
\hline Positive & $8 \quad(8.79 \%)$ & $16(17.58 \%)$ & \\
\hline Negative & $6 \quad(6.59 \%)$ & $62(68.13 \%)$ & \\
\hline Seminal vesicle invasion & & & 0.4201 \\
\hline Positive & $2(2.19 \%)$ & $6 \quad(6.59 \%)$ & \\
\hline Negative & $12(13.19 \%)$ & $72(79.12 \%)$ & \\
\hline Surgical margin & & & 0.1435 \\
\hline Positive & $6 \quad(6.45 \%)$ & $19(20.43 \%)$ & \\
\hline Negative & $8 \quad(8.60 \%)$ & $60(64.51 \%)$ & \\
\hline Lymph node metastasis & & & 0.0172 \\
\hline Positive & $4 \quad(4.21 \%)$ & $6 \quad(6.32 \%)$ & \\
\hline Negative & $10(10.53 \%)$ & $75(78.95 \%)$ & \\
\hline TNM & & & 0.2264 \\
\hline II & $7 \quad(7.37 \%)$ & $58(61.05 \%)$ & \\
\hline III & $5 \quad(5.27 \%)$ & $17(17.89 \%)$ & \\
\hline IV & $2(2.10 \%)$ & $5 \quad(5.26 \%)$ & \\
\hline
\end{tabular}

Histologic grade, High $=$ Gleason grade $5+5,5+4,4+5,4+4,4+3$. Histologic grade, Low $=$ Gleason grade $2+3,3+2,3+3,3+4$.

\section{Ratio of expression level of SSTR mRNA (PC3 \& DU145/LNCap)}

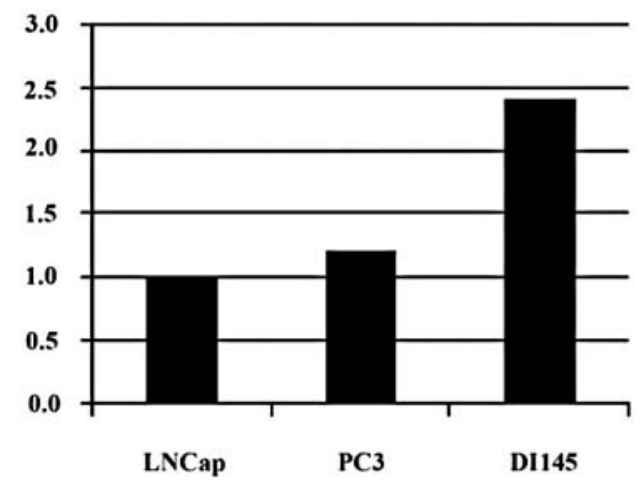

Figure 2. Expression level of SSTR2 mRNA (ratio to GAPDH) in DU145, PC3 and LNCap cell samples.

serum-free medium (DMEM/F12) were added to a BD BioCoat $^{\mathrm{TM}}$ Matrigel $^{\mathrm{TM}}$ Invasion Chamber (BD Biosciences, Franklin Lakes, NJ) and incubated at $37^{\circ} \mathrm{C}$ for $60 \mathrm{~h}$ (DU145 cells) or $48 \mathrm{~h}$ (PC3) over a lower chamber containing $10 \%$ FCS/migration buffer. After removing the Matrigel and cells of the upper membrane, cells on the lower surface were fixed and stained with Diff-Quik (International Reagent), and counted using the KS-400 Image Analyzer System (Carl Zeiss). Rho kinase-inhibitor Y-27632 $\left(10^{-4} \mathrm{M}\right)$ was also used alone or in combination with Octreotide to treat the DU145 cells. Fixation, staining, and cell counting were performed at $60 \mathrm{~h}$ after incubation, as described above.

Cell proliferation assay. DU145 and PC 3 cells $\left(5 \times 10^{4}\right.$ cells/ $500 \mu \mathrm{l}$ per dish) were seeded in $10 \%$ FBS medium with increasing doses of Octreotide at final concentrations of $10^{-5} \mathrm{M}$, $10^{-6} \mathrm{M}, 10^{-7} \mathrm{M}, 0$, and $10^{-6} \mathrm{M}, 10^{-7} \mathrm{M}, 10^{-8} \mathrm{M}, 0$, respectively, for 24,48 and $72 \mathrm{~h}$ in 24-well culture plates. Cell Counting kit-8 (Dojindo, Kumamoto, Japan) was used to calculate the cell numbers.

Visualization of focal adhesions, stress fibers, and microtubules. DU145 and PC3 cells $\left(2.0 \times 10^{4}\right.$ cells) were plated on 4 chamber slides, incubated at $37^{\circ} \mathrm{C}$ for $24 \mathrm{~h}$, treated with Octreotide $\left(10^{-4} \mathrm{M}\right)$ or Octreotide $\left(10^{-4} \mathrm{M}\right)+$ Rho kinase inhibitor Y-27632 (10-4 M, Calbiochem, Darmstadt, Germany) at $37^{\circ} \mathrm{C}$ for $30 \mathrm{~min}$, and then fixed. After washing with $10 \mathrm{nM}$ PBS containing $0.3 \%$ Triton X-100 and blocking with $10 \%$ goat serum/TPBS, cells were incubated with anti-vinculin antibody (Sigma-Aldrich, St. Louis, MO) and anti- $\alpha$ tubulin antibody (Cell Signaling, Danvers, MA) at $4^{\circ} \mathrm{C}$ overnight, and stained with FITC-conjugated anti-mouse IgG at room temperature for $2 \mathrm{~h}$. Cells were further stained with rhodamine phalloidin (Cytoskeleton, Denver, USA) at room temperature for $20 \mathrm{~min}$. Cells were mounted with ToTo-3 in DABCOcontaining medium, and examined under a META system (Carl Zeiss). 


\section{DU145}
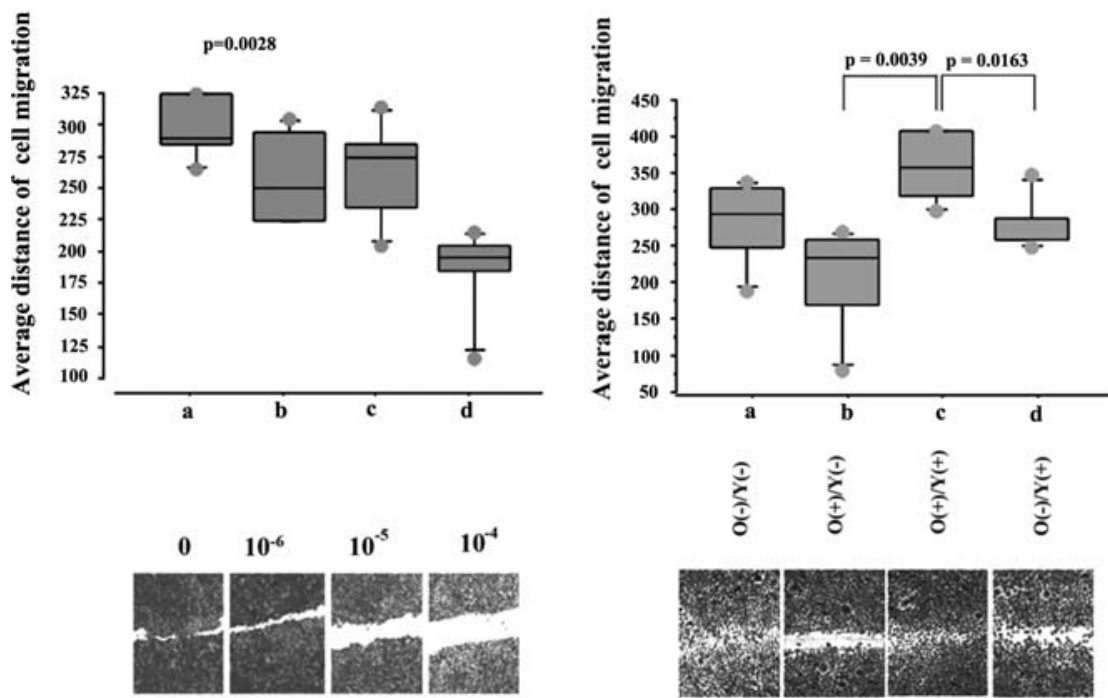

A

$\mathbf{B}$

b

\section{PC 3}
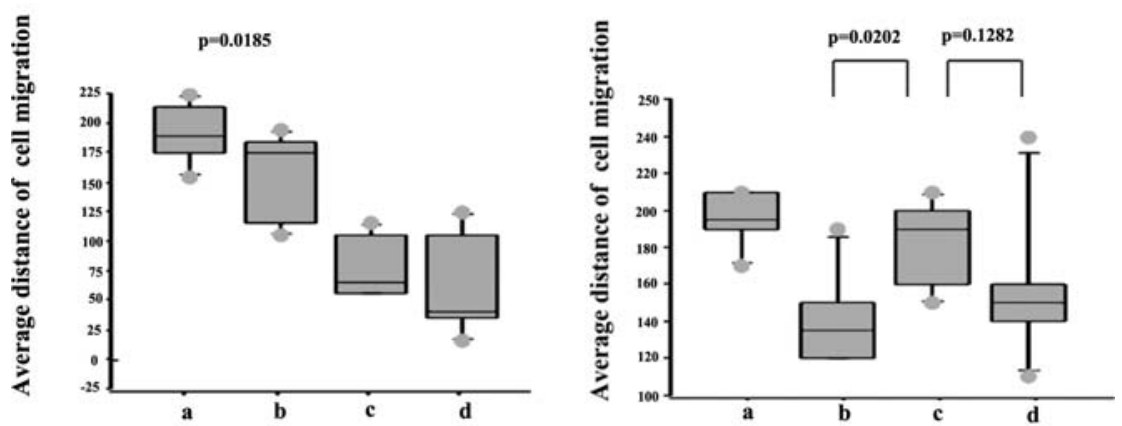

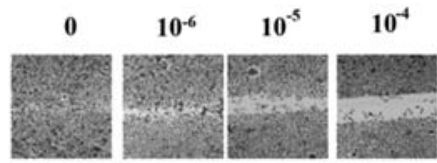

A

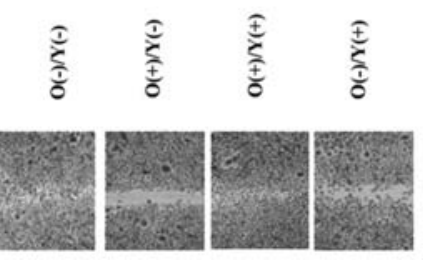

B

Figure 3. (a) Panel A. Migration of DU145 cells after wounding was inhibited by Octreotide in a dose-dependent manner (Kruskal-Wallis test, $\mathrm{p}=0.0028$ ) (a 0, b $10^{-6} \mathrm{M}, \mathrm{c} 10^{-5} \mathrm{M}, \mathrm{d} 10^{-4} \mathrm{M}$ ). Panel B. The inhibition was reversed by Y-27632 (Mann-Whitney U test, b and c, p=0.0039). Although the Y-27632 alone also inhibited cell migration, the disturbance by $\mathrm{Y}-27632$ was significant $(\mathrm{Mann}-$ Whitney $\mathrm{U}$ test, c and d, p=0.0163). [a O(-)/Y(-), b O(+)/Y(-), c O(+)/Y(+), d O(-)/ $\mathrm{Y}(+)$ ]. (b) Panel A. Migration of PC3 cells after wounding was inhibited by Octreotide in a dose-dependent manner (Kruskal-Wallis test, $\mathrm{P}=0.001)$ (a 0 , b $10^{-4} \mathrm{M}$, c $\left.10^{-5} \mathrm{M}, \mathrm{d} 10^{-6} \mathrm{M}\right)$. Panel B. The reversed inhibition by $\mathrm{Y}-27632$ was not significant in $\mathrm{PC} 3 \mathrm{cells}(\mathrm{b}$ and $\mathrm{c}, \mathrm{p}=0.0202, \mathrm{c}$ and $\mathrm{d}, \mathrm{p}=0.1282)$. [a $\mathrm{O}(-) / \mathrm{Y}(-), \mathrm{b}$ $\mathrm{O}(+) / \mathrm{Y}(-), \mathrm{c} . \mathrm{O}(+) / \mathrm{Y}(+), \mathrm{d} . \mathrm{O}(-) / \mathrm{Y}(+)]$.

Statistical analysis. Statistical analysis was performed by StatView using the Mann-Whitney U test and Kruskal-Wallis test. Statistical significance was set at $\mathrm{p}<0.05$.

\section{Results}

Immunohistochemistry. SSTR2a expression was identified in 14 of the 95 cases $(14.74 \%)$. The histological grade (Gleason) and tumor stage (capsular invasion) of the prostate cancer were directly related to SSTR2a expression (Mann-Whitney $\mathrm{U}$ test, $\mathrm{p}=0.0026$ and $\mathrm{p}=0.0041$, respectively). Among the ten cases of lymph node metastasis, SSTR2 expression was higher in frequency than in the 85 non-metastatic cases (MannWhitney U test, $\mathrm{p}=0.0172$ ) (Fig. 1, Table I). SSTR2a staining was shown on most of the metastatic adenocarcinoma cells in lymph nodes in 3 of the 4 cases, while in prostate glands, 

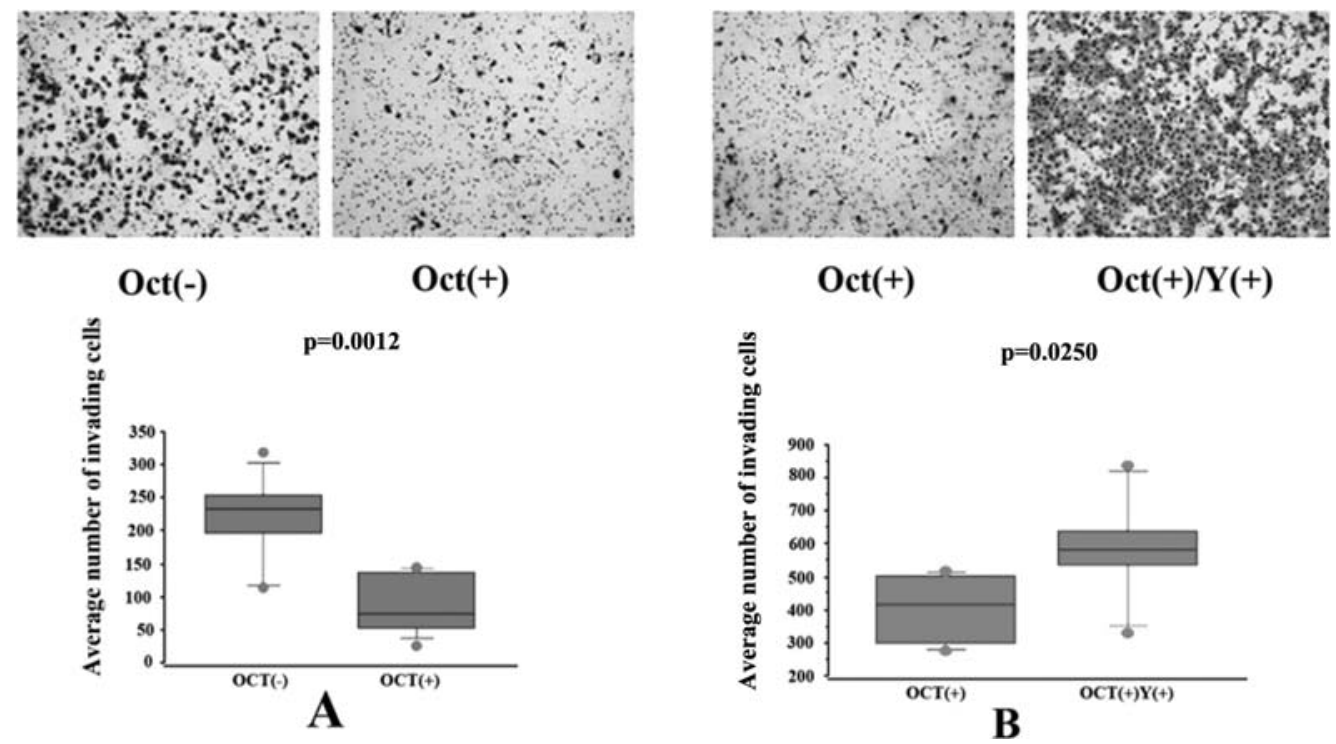

Figure 4. Invasion assay of DU145. (A) Octreotide inhibited invasion of DU145 cells (Mann-Whitney U test, $\mathrm{P}=0.0012$ ). (B) The inhibition was reversed by Y-27632 (Mann-Whitney U test, $\mathrm{P}=0.025$ ).

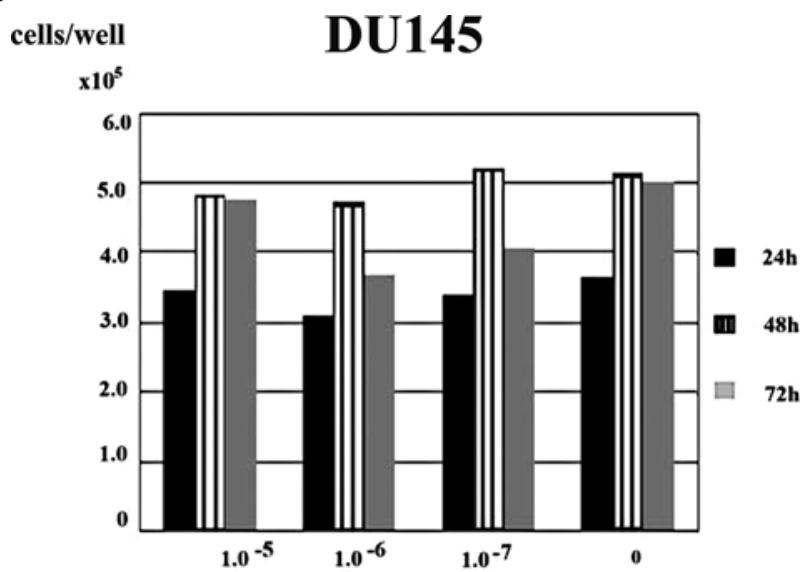

b

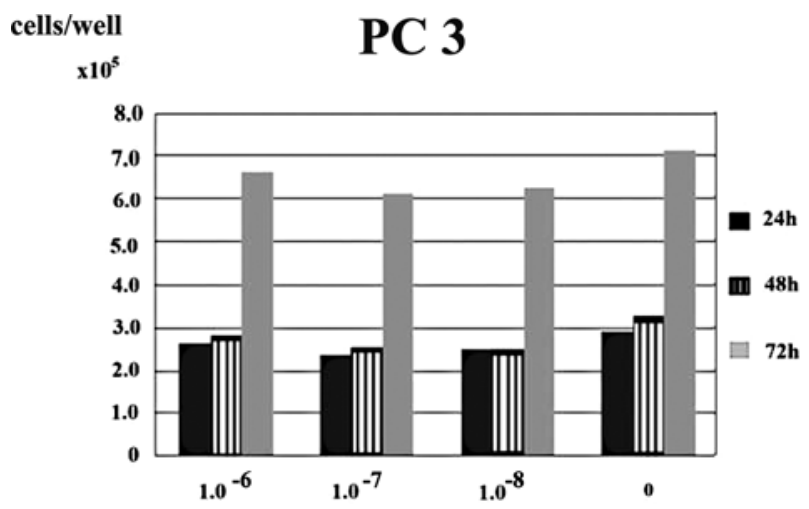

Figure 5. In the proliferation assay, treatment with increasing doses of Octreotide at final concentrations of $10^{-5} \mathrm{M}, 10^{-6} \mathrm{M}, 10^{-7} \mathrm{M}$, and 0 in DU145 (a) and $10^{-6} \mathrm{M}, 10^{-7} \mathrm{M}, 10^{-8} \mathrm{M}$, and 0 in PC3 (b) for 24, 48 and $72 \mathrm{~h}$ in 24-well culture plates had no effect on cell proliferation.

SSTR2a expression was identified in some of the carcinoma cells. However, in one of the 4 cases of lymph node metastasis, the carcinoma cells in lymph node did not express SSTR2a, and SSTR2a-positive carcinoma cells were scattered in the prostate.

Quantitative real-time PCR (RT-PCR). SSTR2 mRNA (ratio to GAPDH) was detected in DU145, PC3, and LNCap cell samples (Fig. 2). RhoA mRNA (ratio to GAPDH) was also detected in DU145, PC3, and LNCap cell samples at 19.439\%, $36.42 \%$, and $20.29 \%$, respectively.

Cell migration, invasion, and proliferation assays. In the wound-healing assay for cell migration, the average distances between the furthest migrated cells to the scraped edge on both sides were measured at $24 \mathrm{~h}$ for DU145 and $12 \mathrm{~h}$ for PC3 after Octreotide $\left(0,10^{-4} \mathrm{M}, 10^{-5} \mathrm{M}\right.$, and $\left.10^{-6} \mathrm{M}\right)$ treatment. The average distances were also measured $24 \mathrm{~h}$ after treatment of both cell types with Octreotide $\left(10^{-4} \mathrm{M}\right)$ alone, Octreotide $\left(10^{-4} \mathrm{M}\right)+\mathrm{Y}-27632\left(10^{-4} \mathrm{M}\right)$, or Y-27632 $\left(10^{-4} \mathrm{M}\right)$ alone. Migration of DU145 and PC3 cells was inhibited by Octreotide in a dose-dependent manner (Fig. 3a, panel A and b, panel A, Kruskal-Wallis test, DU145, $\mathrm{p}=0.0028 ; \mathrm{PC} 3, \mathrm{p}=0.0185)$, and this inhibition was reversed by Y-27632 (Fig. 3a, panel B and $b$, panel B, Mann-Whitney U test, DU145, $\mathrm{p}=0.0039$; PC3, $\mathrm{p}=0.0202)$. Although the $\mathrm{Y}-27632$ alone also inhibited cell migration, the disturbance by $\mathrm{Y}-27632$ in DU145 was significant, but was not significant in PC3 (Fig. 3a, panel B and $\mathrm{b}$, panel B, Mann-Whitney $\mathrm{U}$ test, DU145, $\mathrm{p}=0.0163$; PC3, $\mathrm{p}=0.1282$ ). 


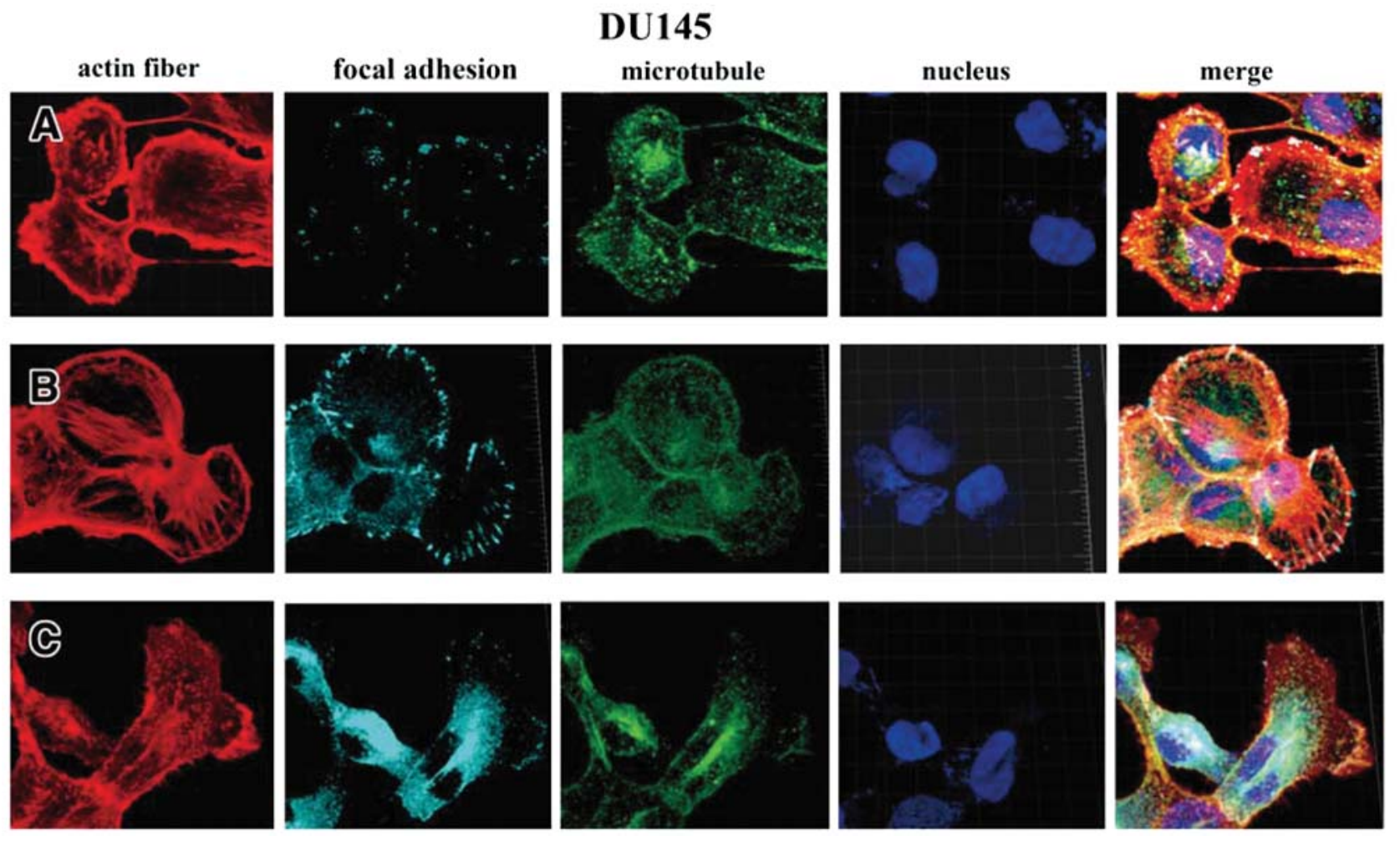

Figure 6. Visualization of focal adhesions and stress (actin) fibers. (A) Expression of actin fibers (rhodamine-phalloidin-positive fibers, red), focal adhesions (vinculin-positive patches, cyan), and microtubules ( $\alpha$-tubulin-positive, green) in DU145 cells was observed. (B) After treatment with Octreotide, excessive formation of actin fibers (rhodamine-phalloidin-positive fibers, red) and focal adhesions (vinculin-positive patches, cyan) was identified in DU145 cells. (C) After treatment with Octreotide and Rho kinase inhibitor (Y-27623), the actin fibers and focal adhesions prominently decreased in number. In contrast, microtubules ( $\alpha$-tubulin-positive, green) showed no significant changes after treatment with Octreotide alone or Octreotide + Rho kinase inhibitor Y-27632 (A-C, third column).

In the invasion assay using Matrigel, the number of invading cells at the reverse side of the membrane was counted. Octreotide inhibited invasion of the DU145 cells (MannWhitney $\mathrm{U}$ test, $\mathrm{p}=0.0012$ ) and PC 3 cells (Mann-Whitney U test, $\mathrm{p}=0.0209)$, and this inhibition was reversed by $\mathrm{Y}-27632$ in the DU145 cells (Mann-Whitney U test, $\mathrm{p}=0.0250$ ) (Fig. 4). In the proliferation assay, treatment with Octreotide had no effect on DU145 and PC3 cell proliferation (Fig. 5a and b).

Visualization of focal adhesions and stress fibers. Excessive formation of focal adhesions (vinculin-positive patches, cyan) and stress fibers (rhodamine-phalloidin-positive staining of actin fiber, red) compared with that of untreated control cells was identified in DU145 and PC3 cells treated with Octreotide. This phenomenon disappeared when we pretreated the cells with the pharmacological Rho kinase inhibitor Y-27632 before application of Octreotide. However, there was no difference in the shape of microtubules ( $\alpha$-tubulin-positive, green) between Octreotide-treated and untreated cells (Fig. 6).

\section{Discussion}

We identified SSTR2a expression in $14.74 \%$ of prostate adenocarcinoma cases, and this expression was related to Gleason grade and prostate capsular invasion. SSTR2aimmunopositive cases of lymph node metastasis were prominently higher in frequency than the non-metastatic cases, although in the SSTR2a (+) cases, SSTR2a expression was identified in only some of the carcinoma cells. These results suggest that the SSTR2a (+) carcinoma cells probably have a stronger tendency for metastasis, and that this phenomenon may be applicable to metastatic or recurrent cases.

To clarify this, additional in vitro studies were performed using the prostate carcinoma cells, DU145 and PC3, both of which expressed SSTR2a. To our surprise, somatostatin analogue (SA) did not inhibit the growth of these prostate carcinoma cells. Instead, it inhibited the migration and invasion abilities of DU145 and PC 3 cells in a dose-dependent manner, and this inhibition was reversed by the Rho kinase inhibitor, Y-27632. Although this inhibition was relatively weak, and the reversed inhibition by Y-27632 was not significant in PC3 cells (Fig. 3b, panel B, b and c, p=0.0202, c and $d, p=0.1282$ ), one explanation for this is that the SSTR2 mRNA in PC3 cells was less than that of DU145 (Fig. 2). Morphological changes of these two cell types after treatment with SA alone or pretreatment with Y-27632 followed by SA treatment corroborated the results of the migration and invasion assays. The results showing that excessive formation of focal adhesions and stress fibers was induced by SA and reversed by Y-27632 treatment suggest that SA changes the shape of prostate carcinoma cells via the Rho-GTPase pathway.

Several observations suggest that RhoA is involved in the regulation of the formation of focal adhesion associated with stress fibers by activating myosin, whereas $\mathrm{Cdc} 42$ and Rac1 
regulate the formation of focal complexes associated with filopodia and lamellipodia, and PAK disassembles focal adhesion and stress fibers $(5,18)$. The balance of activities between the different Rho-GTPase family members and the signaling downstream of Rho determine the final patterns of adhesion and cytoskeletal organization $(5,19)$. Rho was also reported to control actin cytoskeletal assembly in prostate carcinoma cells (20). In PC3 prostate cancer cells, it is suggested that coordinated activation of the individual Rho proteins, RhoC, Rac 1, and RhoA, is required for migration, invasion, and tumor cell diapedesis (21). It is not well understood how intracellular signals through SSTR2a induce excessive focal adhesion. In fibroblast and human umbilical vein endothelial cells, somatostatin was shown to interact with SSTR1 to inhibit Rho activity and cell migration (9). Furthermore, in neuroendocrine cells, somatostatin induces rapid contraction, which is dependent on Rho kinase (10).

Coinciding with the observations that SA did not inhibit the growth of prostate carcinoma cells, the shape of microtubules did not differ between SA-treated and untreated cells. It is known that separate pathways can mediate cell adhesion and the growth-promoting action of Rho (4). Thus, SA appeared to only regulate the shape of the androgenindependent PC3 and DU145 cells, but did not inhibit their proliferation activity, which is probably induced by another Rho pathway. On the other hand, a phase II clinical study on hormone-refractory prostate cancer cases for 4-6 months showed an equivalent effect between a combination therapy using somatostatin analogue combined with LHRH analogues and chemotherapy (22). It was also reported that the amounts of SSTR1-4 mRNA increased after stimulation by somatostatin in LNCap prostate cancer cells (15).

In conclusion, SAs may be beneficial for patients with advanced prostate carcinoma or to protect from distal metastasis if they are positive for SSTR2a. Our study provides evidence that treatment with SA in combination with hormonal or other therapies can simultaneously inhibit prostate cancer growth and provide protection against metastasis.

\section{Acknowledgements}

We would like to thank Mr. Hideo Tsukamoto and Mrs. Yoshiko Itoh for their technical help in cell culture, cell proliferation assay, and immunohistochemistry (Tokai University School of Medicine, Isehara Teaching and Research Support Center), Mr. Kamiguchi (Tokai University School of Medicine, Isehara Teaching and Research Support Center) for his skillful technical assistance in RT-PCR, and Mrs. Hanako Hirabayashi (Tokai University School of Medicine) for immunohistochemistry. Sandostatin (Octreotide) was kindly provided by Novartis Pharma AG. A part of this study was performed in collaboration with Novartis, and the somatostatin analogue reagent, Sandostatin (Octreotide), was generously provided by Novartis Pharma AG (NIBR, Material Transfer Management, WSJ-386.12.06-12.12, Novartis Campus, Forum 1, 4056 Basel, Switzerland).

\section{References}

1. Weckbecker G, Lewis I, Albert R, et al: Opportunities in somatostatin research: biological, chemical and therapeutic aspects. Nat Rev/Drug Discovery 2: 999-1017, 2003.
2. Florio T: Somatostatin/somatostatin receptor signaling: Phosphotyrosine phosphatases. Mol Cell Endocrinol 286: 40-48, 2008.

3. Lahlou H, Saint-Laurent N, Esteve JP, et al: sst2 Somatostatin receptor inhibits cell proliferation through RAS-, Rap1-, and B-raf-dependent ERK2 activation. J Biol Chem 278: 39356-39371, 2003.

4. Narumiya S: The small GTPase Rho: cellular functions and signal transduction. J Biochem 120: 215-228, 1996.

5. Kaverina I, Krylyshkina O and Small JV: Regulation of substrate adhesion dynamics during cell motility. Int J Biochem Cell Biol 34: 746-761, 2002.

6. Enomot T: Microtubules disruption induces the formation of actin stress fibers and focal adhesions in cultured cells: possible involve-ment of the Rho signal cascade. Cell Struct Funct 21: 317-326, 1996.

7. Raman N and Atkinson SJ: Rho controls actin cytoskeletal assembly in renal epithelial cells during ATP depletion and recovery. Am J Physiol 276: C1312-C1324, 1999.

8. Ishizaki T, Uehata M, Tamechika I, et al: Pharmacological properties of Y-27632, a specific inhibitor of Rho-associated kinases. Mol Pharmacol 57: 976-983, 2000.

9. Buchan AM, Lin CY, Choi J, et al: Somatostatin, acting at receptor subtype 1, inhibits Rho activity, the assembly of actin stress fibers, and cell migration. J Biol Chem 277: 28431-28438, 2002.

10. Saras J, Grönberg M, Stridsberg M, et al: Somatostatin induces rapid contraction of neuroendocrine cells. FEBS Lett 581: 1957-1962, 2007

11. Rubin MA: Targeted therapy of cancer: new roles for pathologists-prostate cancer. Mod Pathol 21: S44-S55, 2008.

12. Hejna M, Schmidinger M and Raderer M: The clinical role of somatostatin analogues as antineoplastic agents: much ado about nothing? Ann Oncol 13: 653-668, 2002.

13. Kosari F, Munz JMA, Savci-Heijink CD, et al: Identification of prognostic biomarkers for prostate cancer. Clin Cancer Res 14: 1734-1743, 2008.

14. Halmos G, Schally AV, Sun B, et al: High expression of somatostatin receptors and messenger ribonucleic acid for its receptor subtypes in organ-confined and locally advanced human prostate cancers. J Clin Endocrinol Metab 85: 2564-2571, 2000.

15. Liu Z, Marquez M, Nilsson S, et al: Incubation with somatostatin, 5-aza decitabine and trichostatin up-regulates somatostatin receptor expression in prostate cancer cells. Oncol Rep 20: 151-154, 2008.

16. Dizeyi N, Konrad L, Bjartell A, et al: Localization and mRNA expression of somatostatin receptor subtypes inhuman prostatic tissue and prostate cancer cell lines. Urol Oncol 7: 91-98, 2002.

17. Plonowski A, Schally AV, Nagy A, et al: Inhibition of PC-3 human androgen-independent prostate cancer and its metastases by cytotoxic Somatostatin Analogue AN-238. Cancer Res 59: 1947-1953, 1999

18. Fukata M, Nakagawa M, Kurda S, et al: Cell adhesion and Rho small GTPases. J Cell Sci 112: 4491-4500, 1999.

19. Watanabe N, Kato T, Fujita A, et al: Cooperation between mDia1 and ROCK in Rho-induced actin reorganization. Nat Cell Biol 1: 136-143, 1999.

20. Papadopoulou N, Charalampopoulo I, Alevizopoulos K, et al: Rho/ROCK/actin signaling regulates membrane androgen receptor induced apoptosis in prostate cancer cells. Exp Cell Res 314: 3162-3174, 2008.

21. Sequeira L, Dubyk CW, Riesenberger TA, et al: Rho GTPases in PC-3 prostate cancer cell morphology, invasion and tumor cell diapedesis. Clin Exp Metastasis 25: 569-579, 2008.

22. Dimopoulos MA, Kiamouris C, Gika D, et al: Combination of LHRH analog with somatostatin analog and dexamethasone versus chemotherapy in hormone-refractory prostate cancer: A randomized phase II study. Urology 63: 120-125, 2004. 